\title{
PHYLOGENETIC RELATIONSHIPS BETWEEN MEMBERS OF AMARANTHACEAE AND CHENOPODIACEAE OF LOWER GANGETIC PLAINS USING RAPD AND ISSR MARKERS
}

\author{
Tui Ray AND S. C. Roy* \\ Department of Botany, Centre of Advanced Study, University of Calcutta, \\ 35, Ballygunge Circular Road, Kolkata-700019, India
}

Key words: Amaranthaceae, Chenopodiaceae, RAPD, ISSR, Phylogenetic relationships

\begin{abstract}
The present study is the first report of phylogenetic relationships between some economically important members of Amaranthaceae and Chenopodiaceae of Lower Gangetic Plains of India, using RAPD and ISSR markers. A total of 293 RAPD and 177 ISSR fragments were generated with 15 (out of 50) decamer arbitrary primers and 11 (out of 30) microsatellite repeat anchored primers, respectively. Mean genetic similarities were estimated at 0.47 and 0.45 using RAPDs and ISSRs, respectively. The members of Chenopodiaceae are separated from those of Amaranthaceae in both the cases. The mantel test between the two Jaccard's similarity matrices gave $r=0.83$, showing good correlation between RAPD and ISSR based similarities. However, in both the dendrograms Celosia sp. showed distant relationships with other amaranths.
\end{abstract}

\section{Introduction}

Amaranthaceae and Chenopodiaceae contain a number of economically important crops and weed species. Among the leafy vegetables Amaranthus gangeticus, A. paniculatus and A. viridis of Amaranthaceae and Basella rubra, Chenopodium album, Spinacia oleraceae and Beta vulgaris of Chenopodiaceae are extensively cultivated in Lower Gangetic Plains of India. Grain amaranth is grown along the whole length of Himalayas and also in the plains of India.

Interspecific and intervarietal hybridization in nature have caused a wide variation in amaranths, differing in pigmentation of plant parts as well as in inflorescence. Wide spread nature of many species and variability have resulted in considerable synonymity (Grant 1959). Chenopodiaceae and Amaranthaceae traditionally have been considered allied based on a shared core floral formula. These two families constituting the present materials have generated many controversies over the years with respect to their taxonomic position and phylogenetic relationships.

Morphological traits are influenced by genotype-environment interactions. Moreover morphological characteristics are usually determined by a small number of genes that may not represent the total genetic diversity within the genome (Brown-Guedira et al. 2000). Therefore, taxonomic groupings based on morphological characteristics may not actually describe the relationships among the different taxa.

With the advent of PCR based DNA markers such as random amplified polymorphic DNA (RAPD) (Williams et al. 1990), it is now possible to survey a large number of loci and ascribe unambiguous taxonomic and genetic relationships among different taxa. Inter-simple sequence repeat (ISSR) (Zietkiewicz et al. 1994) markers are useful in detecting genetic polymorphisms and are simpler to use than simple sequence repeat (SSR) technique as prior knowle dge of the target sequences flanking the repeat regions is not required (Zietkiewicz et al. 1994). Though ISSR has been recognized as useful molecular markers in this purpose, it has never been used in phylogenetic study of amaranths and chenopods. The aim of this study was to clarify the phylogenetic relationships among different economically important taxa of Amaranthaceae and Chenopodiaceae available in Lower Gangetic Plains of India with the help of RAPD and ISSR markers.

\footnotetext{
*Author for correspondence. E-mail: scroyind@yahoo.com
} 


\section{Materials and Methods}

Three leafy vegetables of amaranths, Amaranthus gangeticus, A. paniculatus and A. viridis, three grain amaranths, Amaranthus hypochondriacus, A. caudatus and A. cruentus, one ornamental plant, Celosia cristata and one weed, Telanthera philoxeroides of Amaranthaceae and four leafy vegetables of Chenopodiaceae Basella rubra, Chenopodium album, Spinacia oleraceae and Beta vulgaris were used in this study. All the accessions were collected in wild from Lower Gangetic Plains of India, except grain amaranths, which were collected from National Bureau of Plant Genetic Resources (NBPGR), ICAR, Pusa, New Delhi, India. Wild plants were identified by Botanical Survey of India, India.

DNA extraction: Genomic DNA was extracted from fresh young leaves of the above mentioned genotypes using the method of Dellaporta et al. (1983) with a little modification.

PCR conditions and gel electrophoresis: RAPD analyses were carried out with 50 decamer primers from Kit A, B, D and E of Operon Technologies, USA while 30 anchored microsatellite primers were obtained from the set \# 9 of University of British Columbia, Canada and some designed in our laboratory. PCR reactions for RAPD and ISSR analyses and gel electrophoresis were done using the method of Ray et al. (2006).

Data analysis: Bands of equal molecular weight and mobility generated by same primer are considered to be of identical locus. Genetic similarities between taxa were measured by the Jaccard's similarity coefficient (1908) and were used to construct dendrogram using the UPGMA (Unweighted pair group method with arithmetic average). Multidimensional principal coordinate analysis (PCA) was also conducted. Details of the data analyses were same as described by Ray et al. (2006). All the statistical analyses were carried out using the NTSYSpc 2.1 (Exeter Software, Setauket, N. Y.) software package (Rohlf 2000).

\section{Results and Discussion}

RAPD analysis: An initial screening resulted in selection of 15 decamer oligonucleotides from 50 primers for estimation of genetic relationships, which produced clear and reproducible amplification products. A total of 293 loci were generated; all of them were polymorphic at intergeneric level. Details of the polymorphism with RAPD primers are given in Table 1. Within Amaranthus $73.7 \%$ bands were polymorphic among the three leafy types, A. gangeticus, A. paniculatus and $A$. viridis and $71 \%$ bands were polymorphic among the grain types. The extent of polymorphism observed among the amaranth and chenopod genotypes by OPA-18 is shown in Fig. 1.

Genetic similarities among all individuals ranged from 0.09 to 0.85 , with a mean similarity of 0.47 . For the RAPD dendrogram, cophenetic correlation was estimated at $r=0.96$, corresponding to a very good fit. In RAPD based dendrogram (Fig. 3a) C. cristata is the most diverse among all the individuals. RAPD markers clearly separated leafy amaranths from grain types. $T$. philoxeroides has been grouped with the leafy amaranths. B. rubra has been separated from the rest of the chenopods and grouped with the amaranths. The results of PCA (Fig. 4a) corresponded well to those from the cluster analysis obtained through UPGMA.

ISSR analysis: Eleven out of 30 ISSR markers were used for estimation of genetic relationships among and within amaranths and chenopods. A total of 177 loci were observed; all of them were polymorphic at intergeneric level. Details of the polymorphism with ISSR primers are given in Table 2. In the genus Amaranthus $42.5 \%$ bands were polymorphic among the three leafy types and $71.6 \%$ bands were polymorphic among the grain types. The ISSR primers produced varying numbers of DNA fragments, depending on their SSR motifs (Fig. 2). Most dinucleotide repeats $(\mathrm{CA})_{8}$ and $(\mathrm{AC})_{8}$ gave good fingerprint patterns. However, $(\mathrm{CA})_{8} \mathrm{~T}$ did not show any amplification indicating that (CA) repeat flanked by either $\mathrm{G}$ or $\mathrm{A}$ and not by $\mathrm{T}$. Though 
some anchored and unanchored trinucleotide repeats produced polymorphism, unanchored tetranucleotide repeats studied in this case did not give any amplification product. A possible explanation of these results is that dinucleotide microsatellites are prevalent in plants while mono-, tri- and tetranucleotide repeats are less common (Wang et al. 1994).

Table 1. RAPD primers scored to draw the phylogenetic relationships between amaranths and chenopods.

\begin{tabular}{cccccc}
\hline & & \multicolumn{2}{c}{ Amaranths* $^{*}$} & \multicolumn{2}{c}{ Chenopods $^{\#}$} \\
\cline { 3 - 6 } Primers & Primer sequence & $\begin{array}{c}\text { Total no. of } \\
\text { loci } \\
\text { generated }\end{array}$ & $\begin{array}{c}\text { No. of } \\
\text { polymorphic loci } \\
\text { with } \%\end{array}$ & $\begin{array}{c}\text { Total no. of } \\
\text { loci } \\
\text { generated }\end{array}$ & $\begin{array}{c}\text { No. of } \\
\text { polymorphic } \\
\text { loci with } \%\end{array}$ \\
\hline OPA04 & AATCGGGCTG & 10 & $10(100)$ & 09 & $09(100)$ \\
OPA06 & GGTCCCTGAC & 19 & $18(94.7)$ & 14 & $14(100)$ \\
OPA08 & GTGACGTAGG & 12 & $12(100)$ & 14 & $14(100)$ \\
OPA10 & GTGATCGCAG & 18 & $17(94.4)$ & 15 & $14(93.3)$ \\
OPA11 & CAATCGCCGT & 11 & $11(100)$ & 08 & $08(100)$ \\
OPA14 & TCTGTGCTGG & 10 & $10(100)$ & 05 & $04(80)$ \\
OPA15 & TTCCGAACCC & 09 & $08(88.9)$ & 12 & $12(100)$ \\
OPA16 & AGCCAGCGAA & 14 & $14(100)$ & 15 & $15(100)$ \\
OPA17 & GACCGCTTGT & 16 & $15(93.75)$ & 17 & $17(100)$ \\
OPA18 & AGGTGACCGT & 24 & $24(100)$ & 14 & $13(92.85)$ \\
OPA20 & GTTGCGATCC & 13 & $13(100)$ & 14 & $14(100)$ \\
OPB03 & CATCCCCCTG & 14 & $14(100)$ & 08 & $08(100)$ \\
OPB04 & GGACTGGAGT & 12 & $12(100)$ & 08 & $08(100)$ \\
OPB07 & GGTGACGCAG & 14 & $13(92.85)$ & 09 & $09(100)$ \\
OPB13 & TTCCCCCGCT & 10 & $09(90)$ & 11 & $10(90.9)$ \\
\hline
\end{tabular}

*Members of Amaranthaceae excluding Celosia cristata and Telanthera philoxeroides.

\#Members of Chenopodiaceae including Basella rubra. Percentage of polymorphism shown in parenthesis.
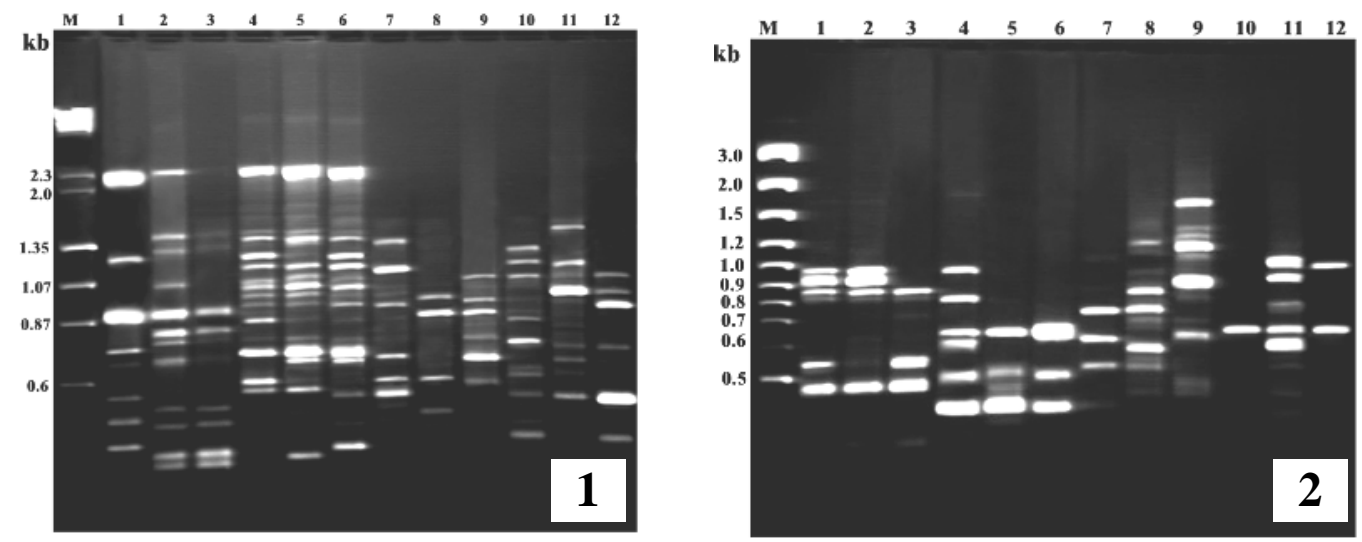

Figs. 1-2: 1. The random amplified polymorphic DNA (RAPD) profile using the primer OPA-18. Lane M $\lambda$ DNA Hind III digest and $\Phi \mathrm{X} 174$ DNA Hae III digest marker. Lanes 1-12: A. gangeticus, A. paniculatus, A. viridis, A. hypochondriacus, A. caudatus, A. cruentus, C. cristata, T. philoxeroides, B. rubra, C. album, S. oleraceae and B. vulgaris, respectively. 2 . The inter-simple sequence repeat (ISSR) polymorphism using the ISSR primer UBC 857. Lane M 100 bp ladder marker. Lanes 1-12: A. gangeticus, A. paniculatus, A. viridis, A. hypochondriacus, A. caudatus, A. cruentus, C. cristata, T. philoxeroides, B. rubra, C. album, S. oleraceae and B. vulgaris, respectively. 
Genetic similarities among all individuals ranged from 0.06 to 0.85 , with a mean similarity of 0.45 . For the ISSR dendrogram, cophenetic correlation was estimated at $r=0.98$, corresponding to a very good fit. In ISSR based dendrogram (Fig. 3b) no group stood out in any special way, thus allowing all the taxa to be in one main cluster, divided into two main subgroups. The first subgroup contains all the taxa except $C$. cristata and $T$. philoxeroides. In this subgroup, all the species of Amaranthus and genera of Chenopodiaceae including B. rubra are clearly separated in two different clusters. Association among the members of Amaranthaceae and Chenopodiaceae examined with principal coordinate analysis (PCA) (Fig. 4b) corresponded well to those from the cluster analysis obtained through UPGMA.

Table 2. ISSR primers scored to draw the phylogenetic relationships between amaranths and chenopods.

\begin{tabular}{lccccc}
\hline & & \multicolumn{2}{c}{ Amaranths } & \multicolumn{2}{c}{ Chenopods $^{\#}$} \\
\cline { 3 - 6 } Primers & $\begin{array}{c}\text { Primer } \\
\text { sequence }\end{array}$ & $\begin{array}{c}\text { Total no. } \\
\text { of loci } \\
\text { generated }\end{array}$ & $\begin{array}{c}\text { No. of } \\
\text { polymorphic loci } \\
\text { with \% }\end{array}$ & $\begin{array}{c}\text { Total no. of } \\
\text { loci generated }\end{array}$ & $\begin{array}{c}\text { No. of } \\
\text { polymorphic } \\
\text { loci with \% }\end{array}$ \\
\hline UBC-825 & $(\mathrm{AC})_{8} \mathrm{~T}$ & 11 & $11(100)$ & 11 & $10(90.9)$ \\
UBC-842 & $(\mathrm{GA})_{8}$ YG & 09 & $09(100)$ & 08 & $08(100)$ \\
UBC-846 & $(\mathrm{CA})_{8}$ RT & 12 & $12(100)$ & 13 & $12(92.3$ \\
UBC-847 & $\mathrm{CA})_{8}$ RC & 11 & $11(100)$ & 07 & $07(100)$ \\
UBC-857 & $(\mathrm{AC})_{8}$ YG & 10 & $10(100)$ & 10 & $10(100)$ \\
UBC-865 & $(\mathrm{CCG})_{6}$ & 05 & $05(100)$ & 06 & $06(100)$ \\
UBC-866 & $(\mathrm{CTC})_{6}$ & 12 & $12(100)$ & 04 & $04(100)$ \\
ISSCR-2 & $(\mathrm{CA})_{8}$ AG & 11 & $11(100)$ & 07 & $06(85.7)$ \\
ISSCR-3 & $(\mathrm{CA})_{8}$ GG & 19 & $18(94.73)$ & 17 & $17(100)$ \\
ISSCR-4 & $(\mathrm{CT})_{8}$ TG & 13 & $13(100)$ & 13 & $13(100)$ \\
ISSCR-5 & $(\mathrm{CA})_{8}$ AC & 12 & $11(91.66)$ & 05 & $05(100)$ \\
\hline Total & & 125 & $123(98.4)$ & 101 & $98(97)$ \\
\hline
\end{tabular}

$\mathrm{R}$ - A and G residues; Y- C and T residues. *Members of Amaranthaceae excluding Celosia cristata and Telanthera philoxeroides. "Members of Chenopodiaceae including Basella rubra. Percentage of polymorphism shown in parenthesis.

Combined analysis: In this study, individual data sets were combined to examine congruence and incongruence among the results. The Mantel test for comparison of the RAPD based and ISSR based similarity matrices showed a good correlation $(r=0.83$ ). Strict consensus tree (Fig. $3 c$ c) was produced to summarize the trees produced by RAPD and ISSR based clustering. The dendrogram clearly separated the 12 individuals of Amaranthaceae and Chenopodiaceae into six different groups (Fig. 3c). The results of PCA analysis combining both RAPD and ISSR data are shown in (Fig. 4c).

Cluster analyses of RAPD and ISSR data using UPGMA revealed that the three leafy amaranth species are closely related, whereas grain amaranths have been separated from the leafy amaranths and together form a separate cluster (Fig. 3a and 3b). High level of RAPD polymorphism in leafy amaranths than grain types is also corroborated by Chan and Sun (1997). Chan and Sun (1997) are of opinion that the relatively high level of RAPD polymorphism in the leafy vegetable species may be the result of their relatively short cultivation history or lack of selection pressure in domestication. Whereas ISSR analysis shows higher level of polymorphism in grain amaranths than leafy vegetables indicating the little effect of selection pressure under domestication on anchored microsatellite repeats.

Despite the great discriminating power of both markers, some differences between the two could be detected. RAPD based clustering (Transue et al. 1994) and hybrid fertility data (Gupta 
and Gudu 1991) indicated that A. caudatus is closely related to A. hypochondriacus. However A. caudatus is more closely related to A. cruentus in ISSR based clustering. On the basis of restriction - site variation in chloroplast and nuclear DNA, Lanoue et al. (1996) also reported that

\section{a. RAPD}
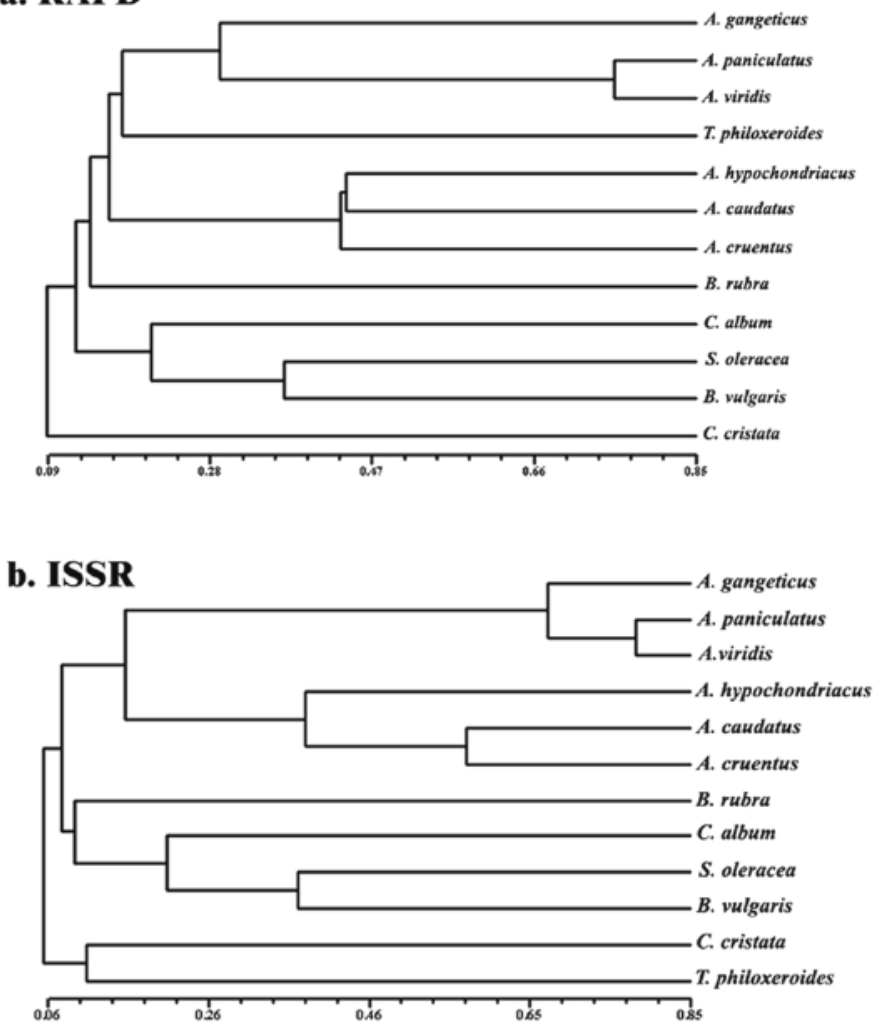

\section{c. Consensus Tree (RAPD+ISSR)}

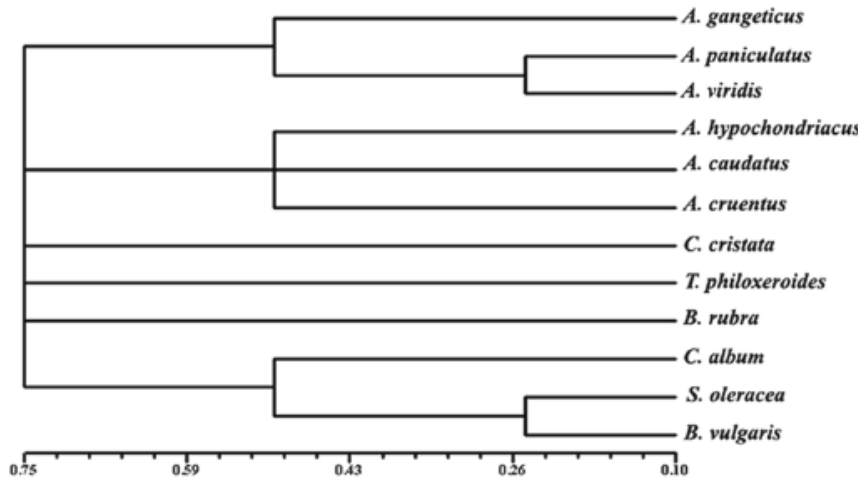

Fig. 3. UPGMA dendrograms of the unweighted pair group method with arithmetic averayıng cluster analysis revealed by a. random amplified polymorphic DNA, b. inter-simple sequence repeats and c. consensus tree of RAPD and ISSR. 


\section{a. RAPD}
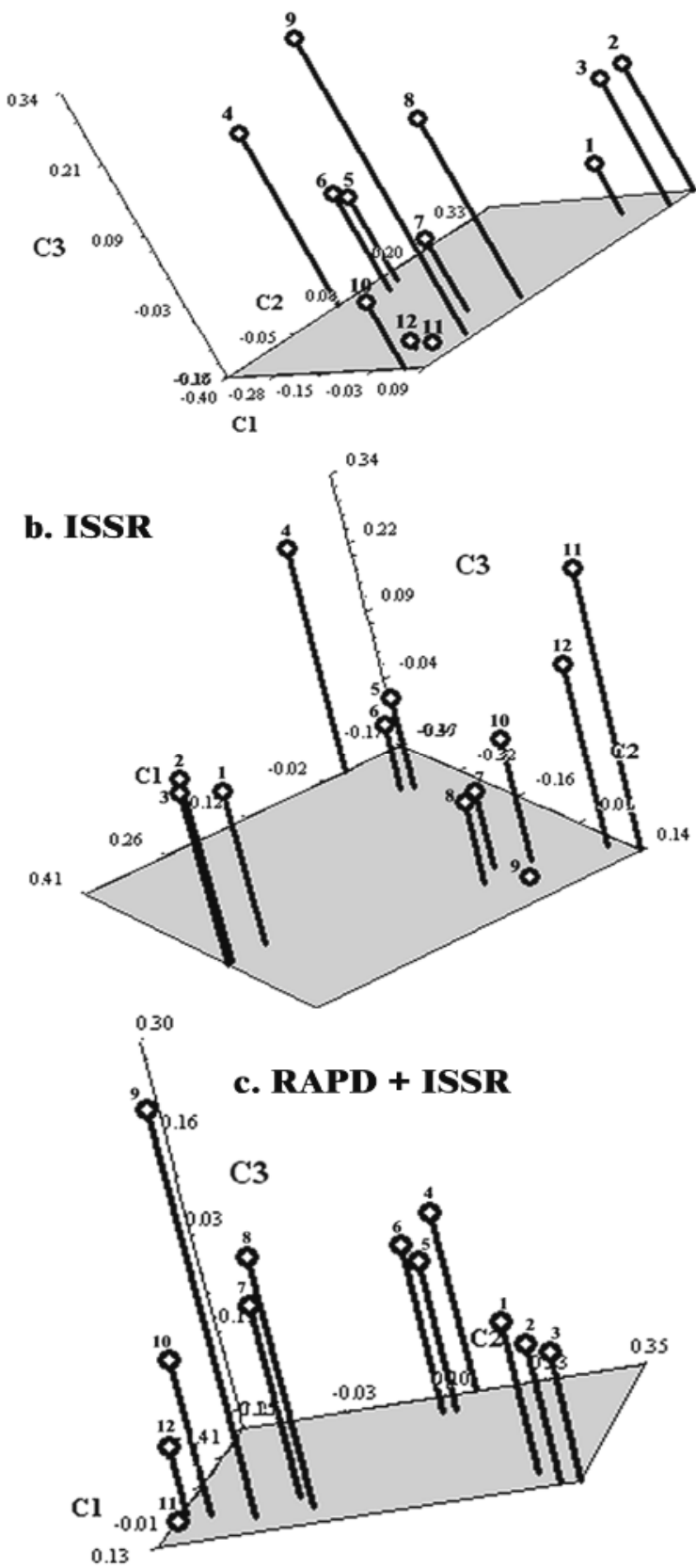

Fig. 4. Three-dimensional plot of PCA using a. random amplified polymorphic DNA, b. inter-simple sequence repeats and c. combined data sets of both RAPD and ISSR. The numbers plotted represents individuals and corresponds to the ones as serially stated for Fig. 1. 
A. caudatus and A. cruentus are more closely related to each other. Position of $T$. philoxeroides also varied in RAPD and ISSR analyses. Such variation may be due to the fact that the PCR amplified profiles in the two marker assays originated from different repetitive and non-repetitive regions of genome. In respect to the position of $T$. philoxeroides, ISSR based clustering is coherent with some morphological characters. Both $T$. philoxeroides and $C$. cristata have papery tepals, bractlets and monadelphous stamens. In this study, both RAPD and ISSR analyses placed Celosia sp. apart from other amaranths. The phylogeny of Amaranthaceae and Chenopodiaceae using the sequence variation of the chloroplast gene $r b c \mathrm{~L}$ also could not infer the position of Celosieae to be recognized as subfamilies and tribes (Kadereit et al. 2003). Basella has generated much attention due to some conflicting reports from the classical taxonomists. Many taxonomists (Bentham and Hooker 1880, Prain 1903) have placed Basella under Chenopodiaceae. While several other taxonomists (Pax and Hoffmann 1934, Cronquist 1968, Takhtajan 1981) placed Basella spp. under a separate family Basellaceae. Though Basella comes in a common cluster with other chenopods in ISSR based dendrogram, the consensus tree based on both RAPD and ISSR data sets shows that Basella is well separated from rest of the chenopods. This supports the separate family status of Basellaceae. The present study supports the separate status of Amaranthaceae and Chenopodiaceae as done by several other classical taxonomists (Bentham and Hooker 1880, Cronquist 1968, Takhtajan 1981) rather inclusion of the members of Chenopodiaceae within Amaranthaceae as done by Cuénoud et al. (2002).

There is no doubt that when morphological variation causes confusion or mis-identification, RAPD analysis alone can aid the correct identification of species in amaranth genetic resources (Transue et al. 1994, Chan and Sun 1997). Although it seems that complementary approaches, such as using both RAPD and ISSR data may provide more accurate information on genetic diversity and phylogenetic relationships between amaranths and chenopods.

\section{Acknowledgements}

The research was funded by the Department of Biotechnology, Govt. of India.

\section{References}

Bentham, G. and J.D. Hooker. 1880. Genera Plantarum. III, Pamplin Reeve \& Co., London. pp. 76-77.

Brown-Guedira, G.L., J.A. Thompson, R.L. Nelson and M.L. Warburton. 2000. Evaluation of genetic diversity of soybean introductions and North American ancestors using RAPD and SSR markers. Crop Sci. 40: 815-823.

Cuénoud, P., V. Savolainen, L.W. Chatrou, M. Powell, R.J. Grayer and M.W. Chase. 2002. Molecular phylogeny of Caryophyllales based on 18S rDNA, rbcL, atpB, and matK. Am. J. Bot. 89: 132-144.

Chan, K.F. and M. Sun. 1997. Genetic diversity and relationships detected by isozyme and RAPD analysis of crop and wild species of Amaranthus. Theor. Appl. Genet. 95: 865-873.

Cronquist, A. 1968. The evolution and classification of flowering plants. Nelson, London, Great Britain. pp. $180-182$.

Dellaporta, S.L., J. Wood and J.B. Hicks. 1983. A plant DNA mini-preparation: version II. Plant Mol. Biol. Rep. 1: 19-21.

Grant, W.F. 1959. Cyto-genetic studies in Amaranthus: III. Chromosome numbers and phylogenetic aspects. Can. J. Gen. Cytol. 1: 313-328.

Gupta, V.K. and S. Gudu. 1991. Interspecific hybrids and possible phylogenetic relations in grain amaranths. Euphytica 52: 33-38.

Jaccard, P. 1908. Nouvelles recherches sur la distribution florale. Bull. Soc. Vaud. Sci. Nat. 44: 223-270.

Kadereit, G., T. Borsch, K. Weising and H. Freitag. 2003. Phylogeny of Amaranthaceae and Chenopodiaceae and the evolution of $\mathrm{C}_{4}$ photosynthesis. Int. J. Plant Sci 164: 959-986.

Lanoue, K.Z., P.G. Wolf, S. Browning and E.E. Hood. 1996. Pylogenetic analysis of restriction- site variation in wild and cultivated Amaranthus species (Amaranthaceae). Theor. Appl. Genet. 93: 722-732.

Pax , F. and K. Hoffmann. 1934. Portulacaceae. In: Die Natürlichen Pflanzenfamilien. 2nd edn., Band 16c (A. Engler and K. Prantl Eds.), pp 234-262. Wilhelm Engelmann, Leipzig. 
Prain, D. 1903. Bengal Plants, Vol.II. Delhi, pp. 877.

Ray, T., I. Dutta, P. Saha, S. Das and S.C. Roy. 2006. Genetic stability of three economically important micropropagated banana (Musa spp.) cultivars of lower Indo-Gangetic plains, as assessed by RAPD and ISSR markers. Plant Cell Tissue and Organ Cult. (online).

Rohlf, F.J. 2000. NTSYS-pc: numerical taxonomy and multivariate analysis system. Exeter Software, Setauket, New York.

Takhtajan, A. 1981. Flowering plants origin and dispersal, 2nd edn. Bishen Singh Mahendra Pal Singh Dehra Dun. pp. 231-214.

Transue, D.K., D.J. Fairbanks, L.R. Robinson and W.R. Andersen. 1994. Species identification by RAPD analysis of grain amaranth genetic resources. Crop Sci. 34: 1385-1389.

Wang. Z., J.L. Weber, G. Zhong and S.D. Tanksley. 1994. Survey of plant short-tandem DNA repeats. Theor. Appl. Genet. 88: 1-6.

Williams, J.G.K., A.R. Kubelik, K.J. Livak, J.A. Rafalski and S.V. Tingey. 1990. DNA polymorphisms amplified by arbitrary primers are useful as genetic markers. Nucleic Acids Res. 18: 6531-6535.

Zietkiewicz, E., A. Rafalski and D. Labuda. 1994. Genome fingerprinting by simple sequence repeat (SSR)anchored polymerase chain reaction amplification. Genomics 20: 176-183.

(Manuscript received on 23 March, 2006; revised on 17 August, 2006) 